УДК 69:692.2:699.86

\title{
МЕТОДИКА ІМОВІРНІСНОГО ОЦІНЮВАННЯ ТЕМПЕРАТУРНОГО РЕЖИМУ СТІН
}

Д-р техн. наук В.А. Пашинський, асп. О.А. Плотніков

\section{МЕТОДИКА ВЕРОЯТНОГО ОЦЕНИВАНИЯ ТЕМПЕРАТУРНОГО РЕЖИМА СТЕН}

Д-р техн. наук В.А. Пашинский, асп. О.А. Плотников

\section{METHODOLOGY THE PROBABLE ESTIMATING OF TEMPERATURE REGIME OF THE WALLS}

Doctor of technical sciences V. Pashynskyi, postgraduate student O. Plotnikov

Розроблена розрахункова методика визначення статистичних характеристик випадкового процесу змін температури внутрішньої поверхні стіни з відомими тепловими характеристиками за статистичними характеристиками температури зовнішнього і внутрішнього повітря. Порівняння 3 даними натурного експерименту вказує на задовільну збіжність результатів.

Ключові слова: огороджувальні конструкиіі, температурний режим, випадкові температурні впливи.

Разработана расчетная методика определения статистических характеристик случайного процесса изменения температуры внутренней поверхности стены с известными тепловыми характеристиками через статистические характеристики температуры наружного и внутреннего воздуха. Сравнение с данными натурного эксперимента дает удовлетворительную сходимость результатов.

Ключевые слова: ограждающие конструкции, температурный режим, случайные температурные воздействия.

We consider the wall of the house with the known thermal characteristics under constant temperature and indoor air temperature random. Based on the known regularity of the heat transfer and attenuation of temperature fluctuations in the thickness of fencing, obtained formulas for the numerical definitions of the mathematical expectation and standard random process temperature changes at the given point of the wall, depending on the relevant numerical characteristics of air temperature. For this wall thickness is divided into layers with constant thickness layer material properties. For each of the layers, the necessary thermal 
characteristics are sequentially determined, the attenuation coefficient of temperature fluctuations, the mathematical expectation and standard process temperature changes on the verge of layers. Mathematical expectation changes in proportion to the thermal resistance of the outer surface of the wall. Changes of standard have exponential character. The calculation results obtained by the method were compared with the results of numerical simulation by finite differences, and the results of natural observations of the temperature of the external and internal air, interior and exterior surface of the wall. Satisfactory convergence of the results confirmed the possibility of using the developed method for evaluating the thermal regime of the walls of their thermal characteristics and meteorological data on air temperature. The method is to be used in assessing the reliability of thermal walling.

Keywords: walling, temperature regime, casual temperature influences.

Вступ. Випадковий характер теплотехнічних характеристик стінових огороджень, а також вплив на них температури атмосферного повітря зумовлює використання імовірнісних методів оцінювання теплової надійності, а складність i невизначеність теплотехнічних процесів в конструкціях 3 випадковими характеристиками зумовлює необхідність широкого застосування експериментальних

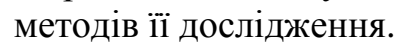

Постановка проблеми. Одним із шляхів удосконалення огороджувальних конструкцій $\epsilon$ аналіз їх теплової надійності в реальних умовах експлуатації. Випадковий характер температурних впливів атмосферного середовища обумовлює необхідність застосування імовірнісних методів оцінювання теплової надійності. Одним з елементів такого оцінювання $\epsilon$ виявлення статистичних характеристик випадкових процесів змін температури огороджувальної конструкції залежно від випадкових змін температури атмосферного повітря.

Аналіз останніх досліджень i публікацій. Норми проектування [1] встановлюють критерії теплових відмов, зокрема падіння температури внутрішньої поверхні огородження нижче точки роси, що може викликати утворення конденсату, а також перевищення допустимої різниці температур внутрішньої поверхні стіни та повітря в приміщенні, що викликає дискомфорт. Наближена методика оцінювання імовірності теплових відмов за вказаними критеріями запропонована в роботі [2]. Детерміновані значення параметрів температури атмосферного повітря, необхідних для виконання теплотехнічних розрахунків, наведені в стандарті [3] для 57 міст України. В статті [10] і монографії [4] проаналізовано й узагальнено дані понад 400 українських метеостанцій, у результаті чого отримані статистичні характеристики квазістаціонарного випадкового процесу температури атмосферного повітря, а також уточнені й деталізовані розрахункові значення температури. Температури в товщі огороджувальної конструкції при стаціонарному тепловому режимі можна визначати аналітично, а при нестаціонарному чисельним методом скінчених різниць, викладеним в [5]. Методика i результати натурних експериментальних досліджень температурного режиму стін житлових будівель викладені в $[6,7]$.

\section{Невирішені частини проблеми.} Методика оцінювання теплової надійності [2] не дозволяе досить точно визначати статистичні характеристики температури внутрішньої поверхні стіни за відповідними характеристиками випадкового процесу температури атмосферного повітря. Саме ця операція $\epsilon$ ключовим елементом методики оцінювання теплової надійності, що вимагає досить простого й точного розв'язання.

Мета дослідження полягає в розробленні методики визначення статистичних характеристик температури в товщі стіни за відповідними характеристиками випадкового процесу температури атмосферного повітря.

Передумови та вихідні залежності. Розглядається огороджувальна конструкція 3 відомими розмірами й тепловими характеристиками усіх шарів. Температура повітря в приміщенні $€$ стаціонарним випадковим процесом 3 відомими статистичними характеристиками, а температуру зовнішнього повітря на невеликому проміжку часу порядку одного місяця можна подати у формі стаціонарного випадкового процесу. Необхідно визначити математичні сподівання й стандарти 
випадкового процесу змін температури на внутрішній поверхні огородження.

В основу розв'язання поставленої задачі покладено методику визначення температур стіни в стаціонарному режимі теплопередачі [5] та методику урахування затухання коливань температури при оцінюванні теплової стійкості огороджувальних конструкцій за [1]. В умовах стаціонарного режиму теплопередачі 3 незмінною температурою зовнішнього повітря температури в середині стіни змінюються пропорційно опору теплопередачі, що виражається відомою формулою, яку зручно записати у вигляді:

$$
\tau_{x}=\tau_{3}+\frac{\tau_{b}-\tau_{3}}{R_{0}} \cdot\left(\frac{1}{\alpha_{3}}+R_{x}\right)
$$

де $\tau_{\beta} i \tau_{3}$ - температури внутрішнього i зовнішнього повітря;

$R_{0}$ - опір теплопередачі огородження;

$R_{x}$ - сумарний термічний опір шарів стіни, розміщених між зовнішньою поверхнею та точкою $з$ координатою X. дорівнюе

Згідно 3 [1], опір теплопередачі стіни

$$
R_{0}=\frac{1}{\alpha_{3}}+\sum R_{i}+\frac{1}{\alpha_{B}}
$$

де $\alpha_{3} i \alpha_{в} \quad$ - коефіцієнти тепловіддачі зовнішньої і внутрішньої поверхні стіни;

$\sum R_{\mathrm{i}}$ - сума термічних опорів усіх шарів огородження.

Статистичні характеристики випадкового процесу змін температури в стіні залежать від теплових характеристик стіни, а також статистичних характеристик випадкових процесів температури зовнішнього та внутрішнього повітря.

Середні значення відображають довготривалу поведінку процесів змін температури, яка еквівалентна стаціонарному тепловому режиму. Тому зміни середніх значень температури по товщі стіни можна виразити на основі (1) у вигляді

$$
M_{x}=M_{3}+\frac{M_{6}-M_{3}}{R_{0}} \cdot\left(\frac{1}{\alpha_{3}}+R_{x}\right) \text {, }
$$

де $M_{x}, M_{3} i M_{6} \quad$ - середні значення температури в точці 3 координатою $\mathrm{X}$, на зовнішній та внутрішній поверхнях стіни; інші позначення відповідають формулі (1).

Випадкові коливання процесів температури відображаються стандартами розподілів ординати цих процесів, які також змінюються по товщині стіни. Для встановлення закономірностей таких змін розглянемо модельну задачу, у якій температура внутрішнього повітря є постійною в часі, а температура зовнішнього повітря змінюється по синусоїді. Такі умови відповідають відомій задачі оцінювання теплостійкості огороджень в літній період, рішення якої викладено в [5] та в нормах проектування [1]. Згідно 3 методикою [1], амплітуда коливань температури внутрішньої поверхні стіни визначається шляхом ділення амплітуди коливань температури зовнішнього повітря на коефіцієнт затухання, залежний від теплофізичних характеристик шарів стіни. Коефіцієнт затухання коливань температури в довільній точці стіни можна визначити на основі формули, наведеної в [1]. Для внутрішньої поверхні одношарової масивної конструкції стіни коефіцієнти затухання коливань зовнішньої та внутрішньої температури можна обчислити за формулами

$$
v_{3}=0,9 e^{0,71 D} \times \frac{\alpha_{3}+s}{\alpha_{3}} \times \frac{s+\alpha_{B}}{2 \times s}, \quad v_{B}=0,9 \times \frac{s+\alpha_{b}}{\alpha_{B}}
$$

де $\alpha_{3}=23 \mathrm{BT} /\left(\mathrm{m}^{2} \cdot{ }^{\circ} \mathrm{C}\right) \quad$ i $\quad \alpha_{\mathrm{B}}=8,7 \mathrm{BT} /\left(\mathrm{M}^{2} \cdot{ }^{\circ} \mathrm{C}\right) \quad-$ коефіцієнти тепловіддачі зовнішньої та внутрішньої поверхні стіни; $s$ - коефіцієнт теплозасвоєння для матеріалу стіни за нормами [1];

$D=R \cdot s-$ показник масивності стіни;

$R=\delta / \lambda$ - термічний опір стіни; 
$\delta$ - товщина стіни;

$\lambda$ - коефіцієнт теплопровідності матеріалу стіни;

У другій формулі (4) враховано, що між внутрішнім повітрям та внутрішньою поверхнею стіни $є$ лише пограничний шар повітря, масивність якого практично дорівнює нулю.

Коефіцієнти затухання (4) дозволяють визначати амплітуду коливань температури внутрішньої поверхні стіни. При дії стаціонарних випадкових процесів температури зовнішнього та внутрішнього повітря зі стандартами $S_{3}$ та $S_{B}$ стандарт розподілу температури внутрішньої поверхні стіни $\epsilon$ пропорційним амплітуді гармонійних коливань і визначається за формулою

$$
S_{X}=\sqrt{\left(S_{3} / v_{3}\right)^{2}+\left(S_{B} / v_{B}\right)^{2}}
$$

яка заснована на правилах додавання незалежних випадкових величин [8] коливань температури, викликаних коливаннями температури внутрішнього та зовнішнього повітря.
В якості контрольного прикладу проаналізовані зміни середніх значень i стандартів температури в стіні житлової будівлі, на якій проводилися експериментальні дослідження [6,7]. Стіна товщиною 350 мм виконана 3 керамзитобетону, який згідно 3 нормами [1] має такі теплотехнічні характеристики: середня густина $\rho=800 \mathrm{\kappa} / \mathrm{M}^{3}$, коефіціснт теплопровідності в нормальних умовах експлуатації $\lambda=0,24$ вт/(м·К), питома теплоємність $\mathrm{C}=0,84$ кДж/(кг·К), коефіцієнт теплозасвоєння $\mathrm{S}=3,83 \mathrm{вт} /\left(\mathrm{m}^{2} \cdot \mathrm{K}\right) .3$ урахуванням вказаних вище коефіцієнтів тепловіддачі зовнішньої та внутрішньої поверхні опір теплопередачі стіни дорівнює $\mathrm{R}=1,62\left(\mathrm{M}^{2} \cdot \mathrm{K}\right) /$ вт. $\quad \mathrm{V}$ процесі експерименту на протязі опалювального періоду систематично вимірювалися температури атмосферного повітря, зовнішньої та внутрішньої поверхні стіни. Отримані реалізації розділені на декадні відрізки, на протязі яких випадкові процеси температури усіх точок можна вважати стаціонарними. У результаті статистичної обробки за методикою $[8,9]$ отримані функції середніх значень i стандартів температури атмосферного повітря, повітря всередині приміщення та внутрішньої поверхні стіни, які наведені в табл. 1.

Таблиця 1

Експериментальні та розрахункові значення статистичних характеристик температури

\begin{tabular}{|c|c|c|c|c|c|c|c|c|}
\hline \multirow{2}{*}{$\begin{array}{c}\text { Номер } \\
\text { декади }\end{array}$} & \multicolumn{3}{|c|}{ Експериментальні значення статистичних характеристик } & \multicolumn{3}{c|}{$\begin{array}{c}\text { Обчислені } \\
\text { значення }\end{array}$} \\
\cline { 2 - 9 } & $\mathrm{M}_{3}$ & $\mathrm{M}_{\mathrm{X}}$ & $\mathrm{M}_{\mathrm{B}}$ & $\mathrm{S}_{3}$ & $\mathrm{~S}_{\mathrm{X}}$ & $\mathrm{S}_{\mathrm{B}}$ & $\mathrm{M}_{\mathrm{X}}$ & $\mathrm{S}_{\mathrm{X}}$ \\
\hline 1 & 9,66 & 21,92 & 23,00 & 3,090 & 0,401 & 0,294 & 22,05 & 0,214 \\
\hline 2 & 4,82 & 22,12 & 23,02 & 2,046 & 0,246 & 0,290 & 21,73 & 0,209 \\
\hline 3 & 4,57 & 22,17 & 23,03 & 4,854 & 0,222 & 0,288 & 21,71 & 0,213 \\
\hline 4 & 1,35 & 22,20 & 23,06 & 4,892 & 0,247 & 0,331 & 21,51 & 0,244 \\
\hline 5 & $-3,94$ & 22,21 & 23,04 & 4,218 & 0,262 & 0,320 & 21,12 & 0,234 \\
\hline 6 & $-2,40$ & 22,21 & 22,98 & 5,242 & 0,257 & 0,329 & 21,18 & 0,243 \\
\hline 7 & $-2,63$ & 22,24 & 23,08 & 4,411 & 0,318 & 0,304 & 21,25 & 0,223 \\
\hline 8 & $-1,63$ & 22,27 & 23,10 & 3,972 & 0,282 & 0,366 & 21,34 & 0,267 \\
\hline 9 & $-3,45$ & 22,28 & 23,03 & 3,796 & 0,303 & 0,340 & 21,15 & 0,247 \\
\hline 10 & 1,50 & 22,27 & 23,07 & 2,880 & 0,341 & 0,344 & 21,54 & 0,249 \\
\hline 11 & $-0,36$ & 22,16 & 22,94 & 2,656 & 0,285 & 0,346 & 21,28 & 0,250 \\
\hline 12 & 0,28 & 22,25 & 23,01 & 3,383 & 0,336 & 0,310 & 21,39 & 0,226 \\
\hline 13 & 0,71 & 22,26 & 23,05 & 4,755 & 0,315 & 0,327 & 21,47 & 0,241 \\
\hline 14 & 1,69 & 22,21 & 22,98 & 5,147 & 0,310 & 0,341 & 21,47 & 0,251 \\
\hline 15 & $-0,46$ & 22,29 & 23,05 & 5,676 & 0,325 & 0,336 & 21,38 & 0,249 \\
\hline 16 & 8,19 & 23,04 & 23,57 & 3,755 & 0,152 & 0,149 & 22,48 & 0,115 \\
\hline
\end{tabular}


Окрім характеристик, визначених за результатами статистичної обробки експериментальних даних, в таблиці 1 наведені також середнє значення й стандарт випадкового процесу змін температури повітря внутрішньої поверхні стіни, обчислені за формулами (3) i (5). При цьому враховані коефіцієнти затухання (4), рівні 89,4 та $v_{B}=1,39$. Аналіз отриманих результатів вказуе на відповідність статистичних характеристик температури внутрішньої поверхні стіни, о обчислених за запропонованою методикою, до відповідних значень, отриманих експериментально. Наявні незначні розбіжності можна пояснити відмінностями реальних теплотехнічних характеристик стіни від наведених вище розрахункових значень, прийнятих за нормами проектування [1] для проектної марки керамзитобетону.

\begin{abstract}
Висновки з дослідження і перспективи, подальший розвиток у даному напрямку:

1. Статистичні

характеристики випадкового процесу змін температури внутрішньої поверхні стіни залежать від статистичних характеристик випадкових процесів температури зовнішнього та внутрішнього повітря.

2. Розроблена методика дозволяє визначати статистичні характеристики випадкового процесу змін температури внутрішньої поверхні стіни через іiі теплотехнічні властивості та статистичні характеристики випадкових процесів температури зовнішнього та внутрішнього повітря.

3. Для отримання досить точних результатів слід використовувати реальні значення теплотехнічних характеристик огороджувальних конструкцій, отримані за результатами випробувань.
\end{abstract}

\section{Список використаних джерел}

1. ДБН В.2.6-31:2006. Конструкції будинків і споруд. Теплова ізоляція будівель [Текст]. - К.: Мінбуд України, 2006. - 66 с.

2. Пашинський, В.А. Оцінка імовірності виникнення теплових відмов конструкцій [Текст] / В.А. Пашинський, Г.Г. Фаренюк // Строительство, материаловедение, машиностроение: Сб. науч. трудов. - Днепропетровск: ДГАСА, 2010. - Вып. 56. - С. 305-310.

3. ДСТУ-Н Б В.1.1-27:2010. Захист від небезпечних геологічних процесів, шкідливих експлуатаційних впливів, від пожежі [Текст] // Будівельна кліматологія. - К., 2010. - 101 с.

4. Температурні впливи на огороджувальні конструкції будівель [Текст]: монографія / В.А. Пашинський, Н.В. Пушкар, А.М. Карюк. - Одеса, 2012. - 180 с.

5. Фокин, К.Ф. Строительная теплотехника ограждающих частей зданий [Текст] / К.Ф. Фокин. - 5-е изд., пересм. - М., 2006. - 256 с.

6. Пашинський, В.А. Методика експериментальних досліджень теплової надійності стінових конструкцій [Текст] / В.А. Пашинський, О.А. Плотніков // Ресурсоекономні матеріали, конструкції, будівлі та споруди: зб. наук. праць. - Рівне, 2012. - Вип. 24. - С. 371-376.

7. Пашинський, В.А. Експериментальні дослідження теплового режиму стін житлових будинків [Текст] / В.А. Пашинський, О.А. Плотніков // Ресурсоекономні матеріали, конструкції, будівлі та споруди: зб. наук. праць. - Рівне, 2013. - Вип. 27. - С. 360-366.

8. Вентцель, Е.С. Теория вероятностей [Текст] / Е.С. Вентцель. - М.: Наука, 1969. - 576 с.

9. Свешников, А.А. Прикладные методы теории случайных функций [Текст] / А.А. Свешников. - М.: Наука, 1968. - 464 с.

10. Пашинський, В.А. Методика оцінювання теплової надійності стін за критерієм тепловитрат [Текст] / В.А. Пашинський, О.А. Плотніков, А.М. Карюк // Наукові нотатки. Міжвуз. зб. (за галузями знань "Машинобудування та металообробка", "Інженерна механіка", "Металургія та матеріалознавство". - Луцьк: ЛНТУ, 2014. - Вип. 45 (травень-червень). - С. 417-423.

Пашинський Віктор Антонович, д-р техн. наук, професор кафедри будівельних, дорожніх машин і будівництва, Кіровоградський національний технічний університет; м. Кіровоград, Україна, просп. Університетський 8, 25030. Тел. 0522-39-04-71. E-mail: pva.kntu@ gmail.com. 
Плотніков Олег Анатолійович, аспірант кафедри будівельних, дорожніх машин і будівництва, Кіровоградський національний технічний університет, м. Кіровоград, Україна, просп. Університетський 8, 25030. Тел. 0522-3904-71. E-mail: Plotnikov-75@ mail.ru.

Pashynskyi V., doctor of technical science, professor; Department of "building, road machines and construction";

Kirovograd National Technical University; Kirovograd, Ukraine, University Avenue 8, 25030. Phone 0522-39-04-71. E-mail: pva.kntu@gmail.com.

Plotnikov O., postgraduate student; Department of "building, road machines and construction"; Kirovograd National Technical University; Kirovograd, Ukraine, University Avenue 8, 25030. Phone 0522-39-04-71. E-mail: Plotnikov75@mail.ru. 